\title{
High tolerance to simulated root herbivory in hydroponically grown cuttings of Salix phylicifolia
}

\author{
Mikhail V. Kozlov ${ }^{1}$ (D) Elena L. Zvereva ${ }^{1}$ (D)
}

Received: 14 October 2020 / Accepted: 10 November 2020 / Published online: 12 February 2021

(C) The Author(s) 2021

\begin{abstract}
The shortage of information regarding the effects of root damage on forest plants, especially trees and shrubs, is the most critical gap in our knowledge of belowground insect herbivory. This study examines how the tea-leaved willow, Salix phylicifolia, responds to simulated root herbivory and how nutrient availability affects these responses. Hydroponically grown cuttings were used to precisely apply the desired levels of root damage. Root: shoot ratios increased proportionally to the intensity of root damage, whereas specific leaf area, leaf water content and chlorophyll fluorescence were not affected. The removal of 2-64\% of roots once in early summer and the removal of $25 \%$ of roots three times during the summer did not change biomass production by cuttings. The repeated removal of 50 and $75 \%$ of roots decreased shoot biomass and, to a lesser extent, total root production. The tolerance of tea-leaved willow to root damage was greater in low nutrient treatment than in high nutrient treatment, thus supporting the Growth Rate Model. According to this model, in low resource conditions plants do not attain their maximum growth rate and therefore have
\end{abstract}

Project funding: This work was supported financially by the Academy of Finland (No. of projects 276,671 and 316,182).

The online version is available at https://www.springerlink.com.

Corresponding editor: Zhu Hong.

Supplementary Information The online version contains supplementary material available at (https://doi.org/10.1007/ s11676-021-01294-z) .

Mikhail V. Kozlov

mikoz@utu.fi

1 Department of Biology, University of Turku, 20014 Turku, Finland a higher capacity for regrowth after damage. We conclude that, in the absence of water limitations, tea-leaved willow shows high tolerance to root losses and is unlikely to be affected by realistic levels of root herbivory.

Keywords Belowground herbivory $\cdot$ Chlorophyll fluorescence $\cdot$ Leaf water content $\cdot$ Plant growth

\section{Introduction}

The importance of belowground herbivory in natural ecosystems is indisputable (Blossey and Hunt-Joshi 2003; Johnson et al. 2016; Gan and Wickings 2020). Still, the vast majority of studies addressing plant responses to belowground herbivory has been conducted on crops, and the shortage of information on responses of forest plants, especially trees and shrubs, to root damage is the most critical gap in our knowledge of belowground insect herbivory (Zvereva and Kozlov 2012). Especially little is known about the effects of minor losses of root biomass (i.e., of background root herbivory) on growth of forest trees (Zvereva and Kozlov 2012; Kozlov and Zvereva 2018). Extending research from agricultural to natural systems will inevitably improve our understanding of mechanisms of plant tolerance and resistance to belowground attacks in the context of the evolutionary arms race between plants and insects (Johnson et al. 2016).

One of the reasons behind a relatively low number of studies exploring the consequences of belowground herbivory is the difficulty of applying controlled levels of root damage to experimental plants (Kozlov and Zvereva 2018). The accurate removal of the desired amount of root biomass can only be done during replanting (Schmid et al. 1990), but this procedure causes transplant shock. Other methods, such as punching holes in soil around plants (Silva and Furlong 2012), cutting 
roots below a certain depth with a sharp blade (Ryalls et al. 2015), or adding herbivores to growth media (Barber et al. 2015) require destructive sampling to estimate the actual level of root removal by comparing root biomass between experimental and control plants. These and other methodological difficulties involved in observations of belowground objects and in their manipulation (Dawson and Byers 2008) explain the relatively slow accumulation of knowledge on the impacts of root herbivory on growth and productivity of plants in natural ecosystems (Zvereva and Kozlov 2012).

Hydroponically grown plants, in contrast to plants grown in soil or in other solid media, offer an excellent opportunity to non-destructively measure root characteristics and precisely apply the desired level of mechanical root damage to simulate belowground herbivory at any stage of plant growth. Nevertheless, plants growing in nutrient solutions have only rarely been used to investigate impacts of root losses on their performance (but see Schmelz et al. 1999; Aldahadha et al. 2012). Willows, which possess high rooting ability (Chmelar 1973), are suitable models for studying effects of root damage on plants in hydroponic experiments.

Willows readily pioneer disturbed sites and, as keystone species, facilitate biodiversity at the landscape level by providing food or shelter for many organisms (Haughton et al. 2016; Tumminello et al. 2018). Many willow species, due to their fast growth and high stress tolerance, are used for habitat restoration (Pezeshki et al. 2007; Sylvain and Mosseler 2017), phytoremediation (McBride et al. 2016; Lebrun et al. 2018) and biofuel production (Karp and Shield 2008; Smart and Cameron 2008). Therefore any factor hampering growth of willows may have not only ecological but also economic importance. Nevertheless, only a handful of studies (Houle and Simard 1996; Endress et al. 2016) have addressed the impacts of root damage on willow performance.

This study explores the effects of simulated root herbivory on biomass production and leaf physiological characteristics of tea-leaved willow, Salix phylicifolia L. This deciduous species grows as a multi-stemmed shrub in a great variety of habitats, including nutrient-poor sites, and is quite common in Northern Europe. We asked: (1) which performance indices of tea-leaved willow are most affected by root damage; (2) which level of root loss is tolerated by this species in terms of above- and below-ground biomass production; and, (3) how do nutrient levels modify the effects of root losses on willow performance.

\section{Materials and methods}

\section{Experiment \#1 (2017)}

This experiment was designed to explore the impacts of realistic levels of root losses on performance of tea-leaved willow and to uncover dose-dependence in these effects. Fifteen cuttings were collected from each of 10 tea-leaved willows naturally growing along the railway in Jäkärlä, Turku $\left(60^{\circ} 32^{\prime} 12^{\prime \prime} \mathrm{N}, 22^{\circ} 21^{\prime} 01^{\prime \prime} \mathrm{E}\right)$ on 5 May 2017, when the uppermost buds in some willow stems were just starting to open. The cuttings were $5-14 \mathrm{~mm}$ in diameter and $23-35 \mathrm{~cm}$ in length.

Two $60 \mathrm{~cm} \times 40 \mathrm{~cm} \times 18 \mathrm{~cm}$ plastic containers were filled with $25 \mathrm{~L}$ of tap water with added liquid fertilizer $(1 \mathrm{~mL} / \mathrm{L}$ of Aqua Vega A and $1 \mathrm{~mL} / \mathrm{L}$ of Aqua Vega B) and $2 \mathrm{~mL} / \mathrm{L}$ of Rhizotronic (Canna International BV, The Netherlands). The resulting solution contained $0.052 \mathrm{~g} / \mathrm{L}$ of nitrogen, $0.011 \mathrm{~g} / \mathrm{L}$ of phosphorous, $0.057 \mathrm{~g} / \mathrm{L}$ of potassium, and other elements ( $\mathrm{Mg}, \mathrm{Ca}, \mathrm{B}, \mathrm{Cu}, \mathrm{Mn}, \mathrm{Mo}, \mathrm{Zn}$ and $\mathrm{Fe}$ ). The solution was renewed every four weeks and was constantly aerated during the experiment.

The base of each cutting was cut obliquely with a sharp knife and the cuttings were inserted into $1-\mathrm{cm}$ thick pieces of ethylene-vinyl acetate mat (Gymstick International Oy, Finland) so that one-third of each cutting was below the mat. These pieces of mat with inserted cuttings were placed into containers so that they floated on the surface of the nutrient solution. The containers with cuttings were put in a passive polyethylene greenhouse to protect the plants from natural herbivory.

The lengths of all roots and shoots produced by our cuttings were measured on 24 May 2017. The cuttings with extreme root and shoot production were excluded, and 105 vigorous cuttings were randomly (with respect to plant genotypes, using random number generator available at www.random.org) attributed to treatments, 15 cuttings per treatment. The treatments included a control and removal of $2 \%, 4 \%, 8 \%, 16 \%, 32 \%$, and $64 \%$ of root biomass (as approximated by root length). The desired amount of root biomass was removed by cutting away one or more rootlets with scissors. The removed root pieces were dried (for $24 \mathrm{~h}$ at $+105^{\circ} \mathrm{C}$ ) and weighed to $0.1 \mathrm{mg}$.

On 23-24 July 2017, i.e., two months after root removal, efficiency of the photosynthetic system II was measured as the ratio between variable fluorescence and maximum fluorescence $\left(\mathrm{F}_{\mathrm{v}} / \mathrm{F}_{\mathrm{m}}\right)$. These measurements were made from three fully developed leaves (taken from lower, middle and upper thirds of the longest shoot of each cutting) after a 30-min period of dark adaptation using a Junior-PAM fluorometer (Walz Heinz GmbH, Effeltrich, Germany) which employs the blue ( $460 \mathrm{~nm}$ ) Power LED for pulse-modulated fluorescence excitation. After measurements, these leaves were weighed, dried, and weighed again. Relative water content was calculated as the weight of water lost from the leaves during drying divided by fresh leaf weight, and specific leaf area (SLA) was calculated as total area of three 12-mm diameter leaf disks taken from these leaves divided 
by their dry weight. Leaves, shoots and roots of each seedling were collected, dried and weighed.

\section{Experiment \#2 (2018)}

This experiment was performed to address the effects of the extreme levels of root loss, which were not considered in the first experiment. Facilities, growth media and measurements were the same as in the first (2017) experiment.

Ten cuttings were collected from each of 10 tea-leaved willow plants on 4 May 2018. The cuttings were $6-14 \mathrm{~mm}$ in diameter and 32-38 cm in length. On 4 June 2018, 90 vigorous cuttings were selected and randomly attributed to one of four treatments, including control and removal of $25 \%$, $50 \%$, and $75 \%$ of root biomass, applied on 4 June, 29 June and 22 July 2018 . The plants were measured and harvested on 8-9 August 2018.

\section{Experiment \#3 (2020)}

This experiment was carried out to explore the effect of nutrient supply on the tolerance of tea-leaved willow to extreme levels of root loss. The treatments were the same as in the second (2018) experiment. To assure replication within the levels of nutrient supply, this experiment was established using four $38 \mathrm{~cm} \times 25 \mathrm{~cm} \times 18 \mathrm{~cm}$ plastic containers each filled with $14 \mathrm{~L}$ of tap water.

We collected 11-12 cuttings from each of 10 tea-leaved willows on 29 April 2020. The cuttings were 5-11 mm diameter and 22-37 cm in length. On 12 June 2020, 100 vigorous cuttings were selected and randomly attributed to one of two levels of liquid fertilizer (high: $1 \mathrm{~mL} / \mathrm{L}$ of Aqua Vega $A$ and $1 \mathrm{~mL} / \mathrm{L}$ of Aqua Vega B; low: $0.2 \mathrm{~mL} / \mathrm{L}$ of Aqua Vega A and $0.2 \mathrm{~mL} / \mathrm{L}$ of Aqua Vega B), and to four treatments nested within these fertilizer levels, including control and removal of $25 \%, 50 \%$, and $75 \%$ of root biomass. These treatments were applied on 12 June, 7 July and 31 July 2020. The plants were measured and harvested on 18 August 2020.

\section{Data analysis}

The impact of root removal on plant performance within each experiment was analysed by mixed model ANOVA (SAS GLIMMIX procedure, type 3 tests; SAS Institute 2009), followed by pairwise comparisons among treatments. A proportion of removed roots (in all experiments) and nutrient levels (only in 2020) were considered as fixed effects and plant genotype (i.e., individual from which cuttings were taken) was considered as a random effect. The number of shoots and leaves was analyzed with the Poisson model, whereas for all other variables the Gaussian model was used. Shoot biomass included newly produced stems and leaves. The final root biomass included only roots collected at the final harvest, whereas the total root biomass included all roots produced by a cutting, including those removed during the experiment. Root: shoot ratios were calculated using the total root biomass. The values of SLA, $\mathrm{F}_{\mathrm{v}} / \mathrm{F}_{\mathrm{m}}$ and leaf water content obtained from three leaves of the same plant were averaged for plant-specific values prior analysis. To facilitate accurate $F$ tests of the fixed effects, standard errors and denominator degrees of freedom in all analyses were adjusted by the latest version of the method described by Kenward and Roger (2009). The significance of the random factor was evaluated by calculating the likelihood ratio and testing it against the chi-squared distribution (as described in Littell et al. 2006).

\section{Results}

Mortality of cuttings was very low (6, 0 and 3 cuttings across different treatments in 2017, 2018 and 2020, respectively) and was therefore not analyzed. The single removal of $2-64 \%$ of roots in early summer did not affect any trait studied with the exception of root: shoot ratio, which increased slightly in response to $8-64 \%$ treatments (Table 1 and Table S1 in supplement materials).

The effects of the repeated removal of 25\%,50\%, and $75 \%$ of roots on plants growing in high-nutrient solution were generally consistent between the experiments conducted in 2018 and 2020 (Fig. 1). The removal of $25 \%$ of roots did not influence either root or shoot production, whereas the removal of $75 \%$ of roots decreased shoot biomass in both years and total root biomass in 2020 only (Table 1; Fig. 1a, $\mathrm{b}, \mathrm{e}, \mathrm{h})$. The consequences of the repeated removal of $50 \%$ of roots varied among performance indices and between study years (Table 1, Fig. 1). The decrease in shoot biomass resulted primarily from the decrease in leaf number, whereas the number of shoots was not affected (Table 1, Tables S2, $\mathrm{S} 3$ in supplement materials).

The cuttings grown in high-nutrient solution (data of 2020; control combined with $25 \%$ treatment) produced $65 \%$ more aboveground biomass than cuttings grown in low-nutrient solution $\left(F_{1,41.0}=4.46, P=0.04\right)$. The level of nutrients modified the effects of root removal $(0-25 \%$ vs. $50-75 \%)$ on both shoot biomass $\left(F_{1,87.6}=5.53, P=0.02\right)$ and the total root biomass $\left(F_{1,87.5}=4.23, P=0.04\right)$. The cuttings grown in high-nutrient media responded to the removal of $50 \%$ and $75 \%$ of roots by significant decreases in both shoot and root biomass production, whereas cuttings grown in low-nutrient media were not affected by these severe treatments (Fig. 1). Root: shoot ratios increased in all treatments proportionally to the intensity of root damage in both high and low nutrition conditions (Fig. 1k-m). None of the treatments affected leaf water content and SLA, whereas 


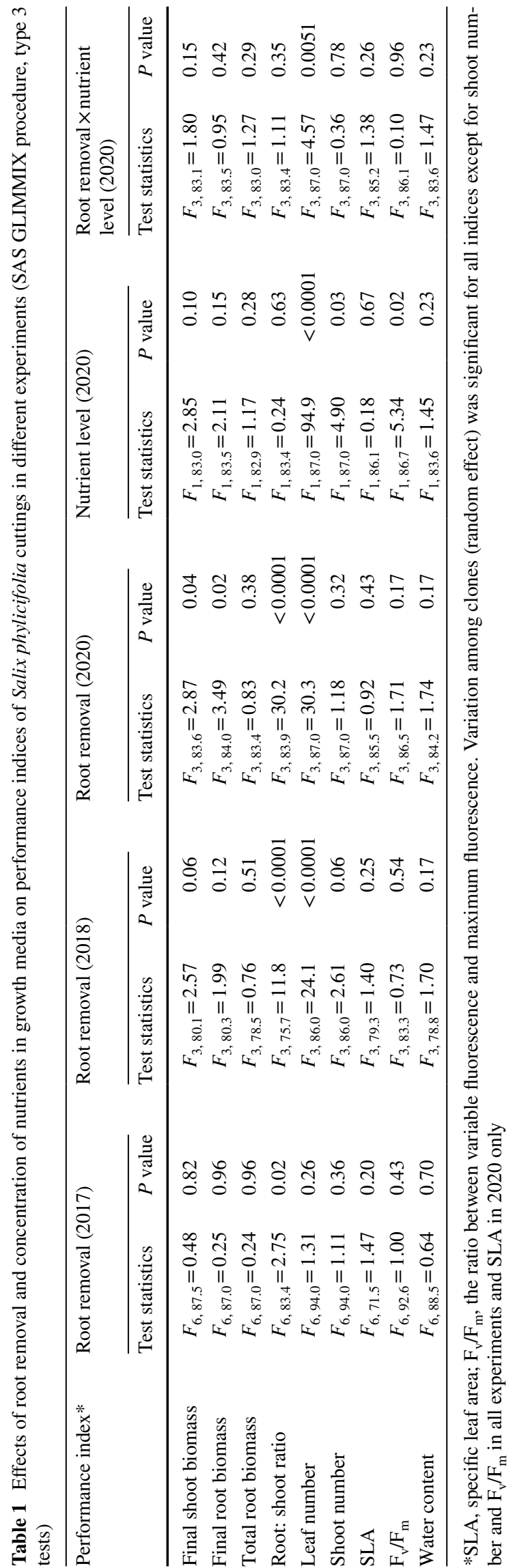

$\mathrm{F}_{\mathrm{v}} / \mathrm{F}_{\mathrm{m}}$ decreased in plants grown in the low-nutrient solution (Table 1, Tables S1-S3 in supplement materials).

Willow clones differed significantly in the majority of performance indices (Table 1), but responded similarly to root removal in terms of aboveground biomass production (interaction terms: $2018, \chi^{2}{ }_{1}=0.00, P=0.95 ; 2020$, $\chi_{1}^{2}=0.96, P=0.16$ ).

\section{Discussion}

Belowground net primary production accounts for 40-70\% of total terrestrial productivity (Vogt et al. 1996). Nevertheless, the processes occurring in the soil are still poorly understood (Copley 2000). This especially concerns interactions between plant roots and soil-dwelling herbivores (Johnson et al. 2016).

Above the ground, insects remove $5-8 \%$ of the leaf area of woody plants annually (Kozlov et al. 2015), whereas there remains considerable uncertainty on the proportion of roots lost to insects in natural ecosystems. Cyr and Pace (1993), by summarizing diverse information, estimated that $13 \%$ of root biomass is annually consumed by all belowground herbivores, including both vertebrates and invertebrates. Ecological field studies reported, on average, the loss of $25 \%$ of root biomass due to natural insect herbivory (Zvereva and Kozlov 2012). However, these studies were presumably conducted when densities of root-feeding insects were exceptionally high, and thus the measured losses, in all likelihood, exceeded the background level (Kozlov and Zvereva 2018). At the same time, the biomass of soil dwelling insect herbivores, in combination with data on their feeding efficiency, suggests that in European forests insects annually consume $0.5 \%$ of their food supply, i.e., of the fine root biomass (Kozel et al. 2017).

This information demonstrates that five of the 6 treatments applied in our first experiment (2\% to $32 \%$ of root biomass removed once in early summer) mimic realistic levels of root herbivory in natural ecosystems. None of these treatments affected growth or physiology of experimental plants, indicating that, in the one-season perspective, biomass production by tea-leaved willow can hardly be affected by root herbivory. This conclusion is in line with the considerably lower effect of root herbivory on aboveground plant characteristics in natural ecosystems relative to agricultural ecosystems (Zvereva and Kozlov 2012).

Willows easily tolerate clipping of $50-100 \%$ of foliage once during the growing season. The only growth response of S. caprea L. and S. myrsinifolia Salisb. to this severe defoliation was a three-fold increase in the number of epicormic shoots (i.e., increase in branching) during the next growing season, whereas leaf size and shoot length were not affected (Zvereva and Kozlov 2001). Biomass of shoots produced by 
Fig. 1 Effects of root removal on biomass (dry weight, estimated marginal means + S.E.) produced by Salix phylicifolia cuttings in $2018 \mathbf{a , ~ d , ~} \mathbf{g}, \mathbf{k}$ and $2020 \mathbf{b}, \mathbf{c}, \mathbf{e}, \mathbf{f}, \mathbf{h}, \mathbf{i}, \mathbf{l}, \mathbf{m}: \mathbf{a}, \mathbf{b}$, c - total aboveground (leaf plus shoot) biomass; $\mathbf{d}, \mathbf{e}, \mathbf{f}-$ final root biomass; $\mathbf{g}, \mathbf{h}, \mathbf{i}$ - total root biomass (including biomass removed in the course of the experiment);k, $\mathbf{l}, \mathbf{m}$ - root: shoot ratio calculated for total biomass; a, b, d, e, g, h, k, l - high concentration of nutrients in growth media; $\mathbf{c}, \mathbf{f}, \mathbf{i}, \mathbf{m}$ - low concentration of nutrients in growth media. Bars with different letters significantly differ from each other $(P=0.05)$. Sample size, 2018: 21-23 plants per treatment; 2020: 12-13 plants per treatment by nutrient level combination
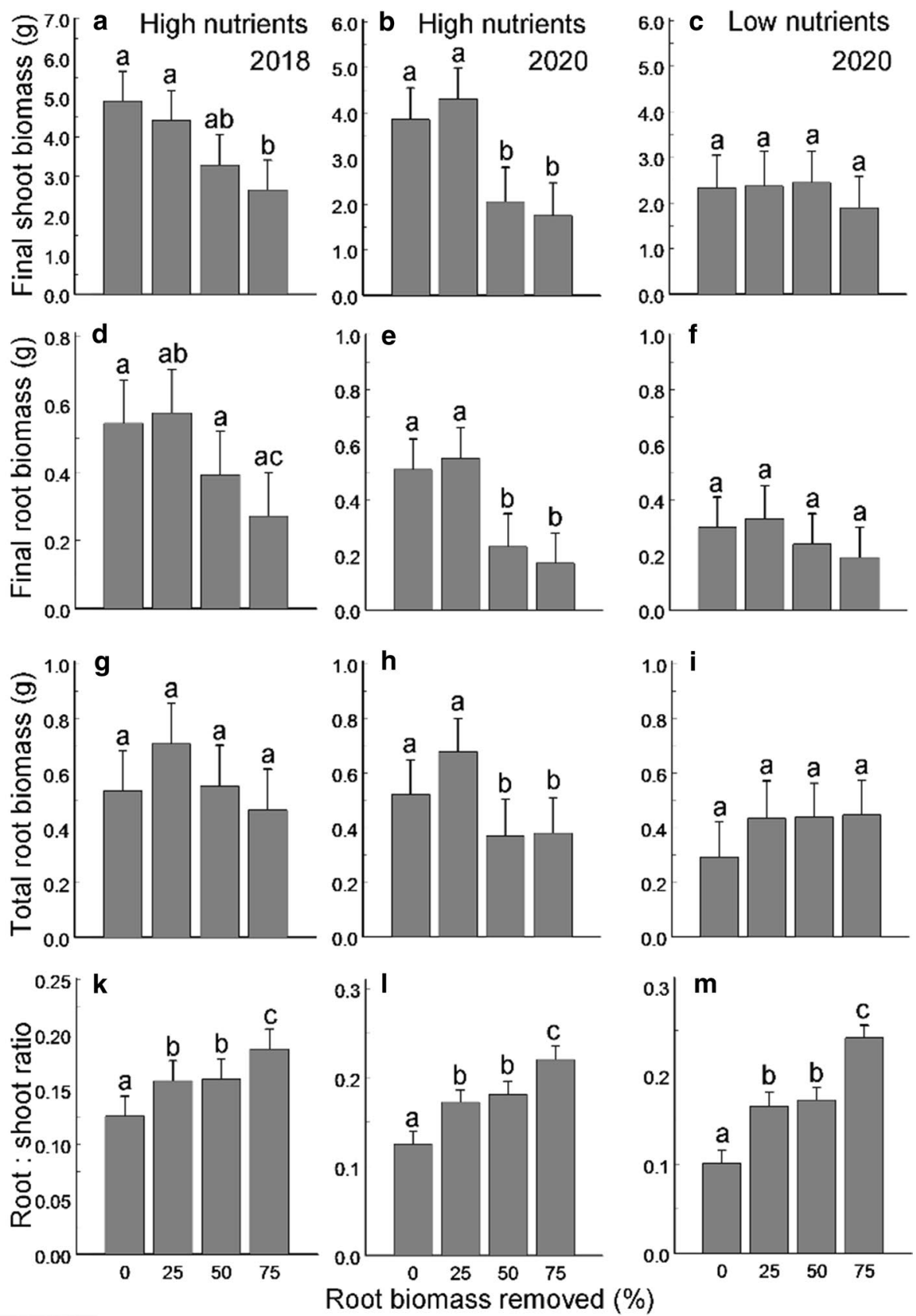

another willow species, S. planifolia Pursh, decreased following $50 \%$ defoliation, but did not change after the removal of $50 \%$ of roots at both high and low fertilisation levels (Houle and Simard 1996). Similarly, removal of $64 \%$ of roots at the beginning of the growing season, as well as removal of $25 \%$ of roots three times during the growing season, did not cause retardation of aboveground growth in tea-leaved willow. The statistically significant decrease in biomass produced by our willow cuttings was observed only in the most severe treatments, i.e., after the repeated removal of $50 \%$ (only in 2020) and 75\% (in both 2018 and 2020) of root biomass. These results, in combination with the outcomes of defoliation experiments (Houle and Simard 1996; Zvereva and Kozlov 2001), indicate that willows compensate equally well for root and leaf herbivory, thus questioning the generality of the conclusion (Johnson et al. 2016) that plants tolerate leaf damage better than root damage.

Several hypotheses have been suggested to explain the effects of resource availability on plant tolerance of herbivory (Wise and Abrahamson 2005, 2007). In our study, willows growing in media with a high concentration of fertilisers produced less aboveground biomass following the repeated removal of $50 \%$ and $75 \%$ of their roots compared with controls, while in media with a low concentration 
of fertilisers, none of the treatments resulted in statistically significant decreases in aboveground biomass production (Fig. 1). This result indicates that tea-leaved willow tolerates higher levels of root damage in low-nutrient conditions compared with high-nutrient conditions, thus supporting the Growth Rate Model (Hilbert et al. 1981). According to this model, in low resource conditions plants do not attain their maximum growth rate and therefore have a higher capacity for regrowth after being damaged, while high-resource media enhance plant growth to the maximum, thus leaving no possibility for compensatory responses (Hilbert et al. 1981). Although the Growth Rate Model has been developed for aboveground herbivory, it can be applied to our results because aboveground biomass production by intact willow cuttings was $65 \%$ higher in high-resource media than in low-resource media. Thus, although an increased supply of nutrients usually mitigates the adverse impact of root herbivory on plants (Gange and Brown 1989; Zvereva and Kozlov 2012), some species adapted to low-resource environments, like tea-leaved willow (Hill et al. 1999), may not benefit from high resource availability in terms of compensatory responses to root damage.

The increase in root: shoot ratio due to intensive root regrowth (Franco et al. 2011) is a typical response to drought and nutrition stress aimed at optimisation of the whole plant growth by intensifying water and nutrient uptake (Bloom et al. 1985). In both low and high nutrition conditions, all treatments caused an increase in root: shoot ratios (Table 1) proportional to the intensity of root damage (Fig. 1k, l, m). This result suggests that extensive root removal caused water and/or nutrition stress in our plants. Importantly, in 2018, even the most severe treatment did not decrease total root biomass, indicating that tea-leaved willow prioritizes root compensatory growth over shoot and leaf production.

Plants often compensate for defoliation by an increase in photosynthesis (Welter 1989; Nykänen and Koricheva 2004), but root herbivory generally leads to a decrease in photosynthesis (Zvereva and Kozlov 2012). However, photosynthesis in hydroponically grown plants, such as wheat (Aldahadha et al. 2012) and tea-leaved willow, did not decrease following root damage. Both these experiments suggest that a decrease in photosynthesis in response to root damage occurs mostly due to water deficit. Consequently, hydroponic experiments may not provide an entire suite of responses to root damage which are observed in plants growing in soil. We therefore have to limit our conclusion on the extreme tolerance of tea-leaved willow to belowground herbivory to the conditions in which plants do not experience water limitations.

Tolerance to herbivory can evolve only if there is variability in responses between plant genotypes (Strauss and
Agrawal 1999). However, absence of interaction between clone (genotype) and treatment effects on aboveground biomass production indicates that genetic variation in tolerance of tea-leaved willow to root herbivory is either minor or not existent. This result is in line with several other studies (Houle and Simard 1996; Barton 2013) which failed to find genetic variations in plant tolerance to herbivory. Therefore, we conclude that the compensatory root regrowth in response to root damage may be a plastic response with little variation in reaction norm among plant genotypes.

One of the most critical limitations of our experiments is their duration. Low levels of insect folivory have long been considered "negligible" for plants based on the results of short-term studies. However, both artificial defoliation and exclusion of herbivores by insecticide application consistently demonstrate that minor losses (2-8\% annually) of leaf area over the long-term substantially reduced aboveground biomass production in North European forest trees (Zvereva et al. 2012; Shestakov et al. 2020). Multiyear experiments addressing root herbivory are relatively rare, and meta-analysis of their outcomes has yielded contradictory results (Zvereva and Kozlov 2012). Woody plants exposed to belowground herbivory during two or more years demonstrated smaller adverse effects relative to single-season experiments, whereas perennial herbaceous plants suffered from stronger adverse effects in long-term studies more than in short-term studies (Zvereva and Kozlov 2012). Therefore, long-term (lasting for at least four years) experiments involving repeated removal of a few percentage of roots are needed to quantify the chronic effects of the realistic levels of belowground insect herbivory on woody plants; but these experiments are difficult to carry out with hydroponically grown plants.

Another factor which also hinders the interpretation of experimental results and their application to natural environments is that terrestrial plants only rarely receive water ad libitum. These two limitations jointly negate the benefits offered by hydroponics to studies addressing impacts of root herbivory on plant growth or reproduction, primarily the possibility to accurately remove the desired amount of plant roots. Nevertheless, plants growing in nutrient solutions may provide good models for short-term experiments addressing rapid physiological and biochemical responses to minor levels of root herbivory and/or transmission of damage-induced signals from roots to leaves.

\section{Conclusion}

In the absence of water limitation, tea-leaved willow shows high tolerance to root losses and is unlikely to be affected by realistic levels of root herbivory. The tolerance of tea-leaved 
willow to root damage decreased with an increase in nutrient availability.

Acknowledgements We thank T. Koivisto and S. Koutaniemi for weighing of samples, T. Klemola for statistical advices, and two anonymous reviewers for their inspiring comments to an earlier draft of the manuscript.

Funding Open Access funding provided by University of Turku (UTU) including Turku University Central Hospital.

Open Access This article is licensed under a Creative Commons Attribution 4.0 International License, which permits use, sharing, adaptation, distribution and reproduction in any medium or format, as long as you give appropriate credit to the original author(s) and the source, provide a link to the Creative Commons licence, and indicate if changes were made. The images or other third party material in this article are included in the article's Creative Commons licence, unless indicated otherwise in a credit line to the material. If material is not included in the article's Creative Commons licence and your intended use is not permitted by statutory regulation or exceeds the permitted use, you will need to obtain permission directly from the copyright holder. To view a copy of this licence, visit http://creativecommons.org/licenses/by/4.0/.

\section{Supplementary file 1 (DOCX 21 kb)References}

Aldahadha AM, Warwick NWM, Backhouse D (2012) Effects of Pythium irregulare and root pruning on water-use efficiency of hydroponically grown wheat under PEG-induced drought. J Phytopathol 160:397-403

Barber NA, Milano NJ, Kiers ET, Theis N, Bartolo V, Hazzard RV, Adler LS (2015) Root herbivory indirectly affects above- and below-ground community members and directly reduces plant performance. J Ecol 103:1509-1518

Barton KE (2013) Ontogenetic patterns in the mechanisms of tolerance to herbivory in Plantago. Ann Bot 112:711-720

Bloom AJ, Chapin FS, Mooney HA (1985) Resource limitation in plants-an economic analogy. Annu Rev Ecol Syst 16:363-392

Blossey B, Hunt-Joshi TR (2003) Belowground herbivory by insects: influence on plants and aboveground herbivores. Annu Rev Entomol 48:521-547

Chmelar J (1973) Propagation of willows by cuttings. New Z J Forestry Sci 4:185-190

Copley J (2000) Ecology goes underground. Nature 406:452-454

Cyr H, Pace ML (1993) Magnitude and patterns of herbivory in aquatic and terrestrial ecosystems. Nature 361:148-150

Dawson LA, Byers RA (2008) Methods for studying root herbivory. In: Johnson SN, Murray PJ (eds) Root feeders-an ecosystem perspective. CABI, Wallingford, pp 3-19

Endress BA, Naylor BJ, Pekin BK, Wisdom MJ (2016) Aboveground and belowground mammalian herbivores regulate the demography of deciduous woody species in conifer forests. Ecosphere 7:e01530

Franco JA, Bañón S, Vicente MJ, Miralles J, Martínez-Sánchez JJ (2011) Root development in horticultural plants grown under abiotic stress conditions-a review. J Horticult Sci Biotechnol 86:543-556

Gan H, Wickings K (2020) Root herbivory and soil carbon cycling: shedding "green" light onto a "brown" world. Soil Biol Biochem 150:107972

Gange AC, Brown VK (1989) Effects of root herbivory by an insect on a foliar feeding species, mediated through changes in the host plant. Oecologia 81:38-42
Haughton AJ, Bohan DA, Clark SJ, Mallott MD, Mallott V, Sage R, Karp A (2016) Dedicated biomass crops can enhance biodiversity in the arable landscape. GCB Bioenergy 8:1071-1081

Hilbert DW, Swift DM, Detling JK, Dyer MI (1981) Relative growth rates and the grazing optimization hypothesis. Oecologia 51:14-18

Hill MO, Mountford JO, Roy DB, Bunce RGH (1999) Ellenberg's indicator values for British plants. ECOFACT Volume 2. Technical Annex. Huntingdon, UK: Institute of Terrestrial Ecology, p 46

Houle G, Simard G (1996) Additive effects of genotype, nutrient availability and type of tissue damage on the compensatory response of Salix planifolia ssp. planifolia to simulated herbivory. Oecologia 107:373-378

Johnson SN, Erb M, Hartley SE (2016) Roots under attack: contrasting plant responses to below- and aboveground insect herbivory. New Phytol 210:413-418

Karp A, Shield I (2008) Bioenergy from plants and the sustainable yield challenge. New Phytol 179:15-32

Kenward MG, Roger JH (2009) An improved approximation to the precision of fixed effects from restricted maximum likelihood. Computat Stat Data Anal 53:2583-2595

Kozel AV, Zvereva EL, Kozlov MV (2017) Impacts of root herbivory on seedlings of three species of boreal forest trees. Appl Soil Ecol 117-118:203-207

Kozlov MV, Zvereva EL (2018) Background insect herbivory: impacts, patterns and methodology. Progress in Botany 79:315-355

Kozlov MV, Lanta V, Zverev V, Zvereva EL (2015) Global patterns in background losses of woody plant foliage to insects. Glob Ecol Biogeogr 24:1126-1135

Lebrun M, Miard F, Hattab-Hambli N, Bourgerie S, Morabito D (2018) Assisted phytoremediation of a multi-contaminated industrial soil using biochar and garden soil amendments associated with Salix alba or Salix viminalis: abilities to stabilize $\mathrm{As}, \mathrm{Pb}$, and $\mathrm{Cu}$. Water Air Soil Pollut 229:163

Littell RC, Milliken GA, Stroup WW, Wolfinger RD, Schabenberger O (2006) SAS for mixed models, 2nd edn. SAS Institute, Cary, USA, p 814

McBride MB, Martinez CE, Kim B (2016) Zn, Cd, S and trace metal bioaccumulation in willow (Salix spp.) cultivars grown hydroponically. Internat J Phytoremediation 18:1178-1186

Nykänen H, Koricheva J (2004) Damage-induced changes in woody plants and their effects on insect herbivore performance: a metaanalysis. Oikos 104:247-268

Pezeshki SR, Li SW, Shields FD, Martin LT (2007) Factors governing survival of black willow (Salix nigra) cuttings in a streambank restoration project. Ecol Engineering 29:56-65

Ryalls JMW, Moore BD, Riegler M, Gherlenda AN, Johnson SN (2015) Amino acid-mediated impacts of elevated carbon dioxide and simulated root herbivory on aphids are neutralized by increased air temperatures. J Exptl Bot 66:613-623

SAS Institute (2009) SAS/Stat. User's guide version 9. 2 Cary. USA: SAS Institute. $\mathrm{p} 7869$

Schmelz EA, Grebenok RJ, Galbraith DW, Bowers WS (1999) Insectinduced synthesis of phytoecdysteroids in spinach, Spinacia oleracea. J Chem Ecol 25:1739-1757

Schmid B, Miao SL, Bazzaz FA (1990) Effects of simulated root herbivory and fertilizer application on growth and biomass allocation in the clonal perennial Solidago canadensis. Oecologia 84:9-15

Shestakov AL, Filippov BYu, Zubrii NA, Klemola T, Zezin I, Zverev V, Zvereva EL, Kozlov MV (2020) Doubling of biomass production in European boreal forest trees by a four-year suppression of background insect herbivory. Forest Ecol Manage 462:117992

Silva R, Furlong MJ (2012) Diamondback moth oviposition: effects of host plant and herbivory. Entomol Exptl Appl 143:218-230

Smart LB, Cameron KD (2008) Genetic improvement of willow (Salix spp.) as a dedicated bioenergy crop. In: Vermerris W (ed) 
Genetic improvement of bioenergy crops. Springer, New York, pp 377-396

Strauss SY, Agrawal AA (1999) The ecology and evolution of plant tolerance to herbivory. Trends Ecol Evol 14:179-185

Sylvain ZA, Mosseler A (2017) Use of shrub willows (Salix spp.) to develop soil communities during coal mine restoration. Can J Forest Res 47:1687-1694

Tumminello G, Volk TA, McArt SH, Fierke MK (2018) Maximizing pollinator diversity in willow biomass plantings: a comparison between willow sexes and among pedigrees. Biomass Bioenergy 117:124-130

Vogt KA, Vogt DJ, Palmiotto PA, Boon P, O’Hara J, Asbjornsen H (1996) Review of root dynamics in forest ecosystems grouped by climate, climatic forest type, and species. Plant Soil 187:159-219

Welter SC (1989) Arthropod impact on plant gas exchange. In: Bernays EA (ed) Plant-insect interactions. CRC Press, Boca Raton, USA, pp 135-150

Wise MJ, Abrahamson WG (2005) Beyond the compensatory continuum: environmental resource levels and plant tolerance of herbivory. Oikos 109:417-428
Wise MJ, Abrahamson WG (2007) Effects of resource availability on tolerance of herbivory: a review and assessment of three opposing models. Am Nat 169:443-454

Zvereva EL, Kozlov MV (2001) Effects of pollution induced habitat disturbance on willow response to simulated herbivory. J Ecol 89:21-30

Zvereva EL, Kozlov MV (2012) Sources of variation in plant responses to belowground insect herbivory: a meta-analysis. Oecologia 169:441-452

Zvereva EL, Zverev VE, Kozlov MV (2012) Little strokes fell great oaks: minor but chronic herbivory substantially reduces birch growth. Oikos 121:2036-2043

Publisher's Note Springer Nature remains neutral with regard to jurisdictional claims in published maps and institutional affiliations. 